\title{
Políticas Públicas: subalternidade como crítica a racionalidade linear
} Public Policies: subordination as criticism of linear rationality

\author{
Cássio Henrique Oliveira Conceição ${ }^{1}$ \\ Breitner Luiz Tavares ${ }^{2}$
}

\section{RESUMO}

O presente artigo busca ampliar a discussão sobre as fronteiras do campo de estudos em políticas públicas, problematizando os conceitos de racionalidade e de ator, na proposta por Harold Lasswell (1951; 1971), então chamada de Policy Orientation, a partir dos pressupostos teóricos da subalternidade, por compreender que ajudariam a discutir as concretas possibilidades de participação deste novo ator nos processos mais decisivos de políticas públicas. Para isso, foi realizada revisão bibliográfica focada nos estudos críticos deste campo, bem como nos estudos relacionados ao pressuposto da subalternidade, incluindo além de Gramsci (2002; 2007), os Subaltern Studies e teóricos da colonialidade/decolonialidade. Feita sistematização dos trabalhos emergiram: as dificuldades para inclusão do subalterno como ator, principalmente ao relacionar-se conceitos como Estado, Argumento e Problema; a incoerência entre a racionalidade por Lasswell e o pressuposto da subalternidade; e, por fim foi apresentada uma discussão não institucional ao processo político comunitário, que teria como agente possível o subalterno.

Palavras-chave: Políticas Públicas; Subalternidade; Racionalidade; Comunidade.

\begin{abstract}
This paper seeks to broaden the discussion on the boundaries of the field of public policy studies, problematizing the concepts of rationality and actor, in the proposal by Harold Lasswell $(1951 ; 1971)$, then called Policy Orientation, based on the theoretical assumptions of subalternity for understanding that they would help to discuss the concrete possibilities of participation of this new actor in the most decisive processes of public policies. For this, a bibliographic review was carried out focused on critical studies of the field, as well as on studies related to the subalternity concepts, beyond Gramsci (2002; 2007), Subaltern Studies and coloniality / decoloniality theorists. After systematization of the papers, emerged: the difficulties to include the subaltern as an actor, mainly when relating concepts as State, Argument and Problem; the inconsistency between rationality by Lasswell and the concepts of subalternity; and, finally, a non-institutional discussion was presented to the community political process, which would have the subaltern as a possible agent.
\end{abstract}

Keywords: Public Policy; Subalternity; Rationality; Community.

\footnotetext{
1 Graduado em Saúde Coletiva pela Faculdade de Ceilândia/Universidade de Brasília, atualmente mestrando no Programa de PósGraduação em Desenvolvimento, Sociedade e Cooperação Internacional. Membro do Programa de Pós-Graduação em Desenvolvimento, Sociedade e Cooperação Internacional/Centro de Estudos Avançados Multidisciplinares - Universidade de Brasília. E-mail: cassiohenrique28@gmail.com.

2 O pesquisador possui graduação em licenciatura em ciências sociais, bacharelado, mestrado e doutorado em sociologia pela Universidade de Brasília. pesquisador, tem doutorado sanduíche na Universidade Califórnia em Berkeley em Estudos Étnicos subsidiado pela Comissão Fulbright. Professor Associado I na Universidade de Brasília, Campus FCE, no curso de Saúde Coletiva. Membro do Programa de Pós Graduação em Desenvolvimento Sociedade e Cooperação Internacional - PPGDSCI. Realizou pesquisa pós doutoral sobre relações raciais e juventude em situação de rua na Leeds Becket University - Reino Unido, no programa de pós graduação: Race, Education and Decolonial Thought em 2018. E-mail: breitner@unb.br.
} 


\section{Introdução}

Para compreender a construção de políticas públicas, bem como discutir suas limitações enquanto processo formativo, deve-se ampliar o olhar não apenas a sua realidade aplicada, mas à sua construção histórica, entendendo seu nascimento e compreendendo, a partir disso, seus entraves epistemológicos. Para isso, o artigo se propõe como crítica à racionalidade por Lasswell $(1951,1971)$, revisando parte do corpo crítico que o campo de estudo de políticas públicas desenvolveu após suas produções, tendo como objetivo: apresentar a proposta teórica do subalterno e discuti-la como contribuição ampliativa ao campo de estudo de políticas públicas, a partir de Gramsci $(2002,2007)$.

A construção do conceito 'Política Pública' é traçada historicamente do termo Policy Analysis, que surge na tentativa de examinar as ações governamentais, principalmente a partir de concepções racionais dentro do campo da Ciência Política nos Estados Unidos (EUA). O responsável por fazê-lo foi Harold Lasswell (1951) que apresenta a Policy Orientation (já apresentada como Policy Science) e pressupõe primeiro, a necessidade da construção de um campo, baseado na análise de políticas (Policy), que abrangesse a importância de conhecimentos multidisciplinares como base; segundo, que entendesse como objeto de estudo, necessariamente, o enfrentamento de problemas, visto como o cerne no qual a Policy estabelece seus objetivos; e terceiro, que esse enfrentamento, bem como seu processo constitutivo seria portanto, construído em cima de parâmetros racionais e positivos.

Em trabalhos posteriores, Lasswell delineia melhor a estrutura de seu campo, colocando seu modelo de análise ainda mais focado ao conhecimento, de maneira que

[...] a ciência política está preocupada com o conhecimento de e no processo decisivo de ordem pública e civil [...] As Ciências Políticas focam a relevância do conhecimento tanto na como da decisão (LASSWELL, 1971, p. 1-2, tradução nossa).

Dessa forma, Lasswell amplia a importância do conhecimento à construção da policy science, entendendo que sua relevância a esse processo não finda na tomada de decisão, mas se perpetua. $O$ autor reafirma a proposta de contexto ampliando a interação social e passa a entender mais fatores como influentes ao processo. Contudo, mesmo ao descrever a importância do conhecimento como transversal ao processo formativo da policy science, ainda mantém sua esfera participativa exclusiva aos 'especialistas', ao governo, e ainda em construção da figura do 'policy maker', afirmando que "o ambiente social é desinteressado no conhecimento como um fim a si mesmo" (LASSWELL, 1971, p. 5, tradução nossa).

Em cima da proposta por Lasswell $(1951,1971)$ desenvolveu-se grande corpo crítico, centrado principalmente: na pouca relevância dada aos processos sociais, que ao aparecerem de maneira tão tímida conformam uma proposta objetivista; na necessidade de uma análise baseada em processos interativos mais amplos; e, principalmente, no excedente foco a racionalidade linear que ao fazê-lo deixa de considerar fatores - durante a construção e análise da política - como as relações de poder e a possibilidade de diferentes fases à análise, impossibilitando a contribuição de atores outros ao processo formativo da política (LINDBLOM, 1959, 1979; TRIBE, 1972).

Acompanhando essa mesma linha crítica, podemos ampliar o campo de estudo de políticas públicas e propor uma analítica multidisciplinar sobre quem de fato constrói essa política pública, se há extratos sociais específicos impedidos de participar dessa construção, e como esse ator, que constrói, representa e influencia a manutenção da realidade sócio-institucional existente. $O$ ator no qual o presente artigo se debruça é a figura do sujeito social subalterno, tentando localizar quem é esse subalterno, e com base no 
processo de dominação como se possibilita sua participação aos processos de decisão estruturados, teoricamente, pela Policy Analisys (GRAMSCI, 2002; LASSWELL, 1951, 1971).

Para isso, o método utilizado foi a revisão de literatura, operada a partir do campo de estudo de políticas públicas partindo de Harold Lasswell (1951), e seguindo em sentido cronológico aos estudos críticos do campo tomado em Fischer (2013), assumindo as principais críticas e reflexões propostas à racionalidade em conjunto ao ator. Expandindo dali, buscou-se a gama de autores os quais discutem teoricamente o subalterno, em que assumimos de Gramsci, também em sentido cronológico, até a relação do subalterno ao conceito de 'comunidade', adentrando as principais reflexões da Colonialidade/Decolonialidade e os subaltern studies. Por fim, realizou-se a sistematização teórica dos estudos, relacionando ambas as propostas para contribuição ao campo de estudo de políticas públicas.

O trabalho está organizado na relação com os conceitos Ator, Estado, Argumento e Problema, apresentados frente a proposta de racionalidade trazida. O texto inicia-se caracterizando o subalterno como proposta teórica, ao mesmo tempo, em que o relaciona aos conceitos de Ator e Estado. Posteriormente é feita relação com o conceito de argumento adentrando mais a caracterização da subalternidade como estado de opressão e a possibilidade de discuti-la em comunidades, realizando por fim, a relação com o conceito de problema e a possibilidade real de contribuição do subalterno nos processos mais decisivos da política pública.

Logo na próxima sessão iniciaremos um debate sobre quem é o subalterno e o pressuposto teórico da subalternidade a partir de Gramsci (GRAMSCI, 2002, 2007). Busca-se ampliar a discussão sobre participação do Estado tanto na construção da política pública, quanto no processo de dominação e subjeção do subalterno, discutindo a expectativa democrática do processo de formação política e sua improbabilidade junto a racionalidade linear.

\section{Políticas Públicas $x$ Estado $x$ Subalterno}

Após a proposta por Lasswell (1951), tida como policy orientation, abordagens múltiplas desenvolveram-se na tentativa de entender sua aplicação, baseadas na formulação prática de ações à policy analysis. Principalmente focadas na intenção de construir um manual que contemplasse as linhas pragmáticas pensadas pelo autor. Essa tentativa a longo prazo se estabelece sob o que passa a ser conhecido como 'ciclo de políticas', consagrando a hegemonia do campo sob um paradigma positivista, que interpreta a realidade política enquadrando-a no ordenamento do ciclo dividido entre: identificação do problema; formação da agenda; formulação de alternativas; tomada de decisão; implementação; avaliação; e extinção (AGUM; RISCADO; MENEZES, 2015; SECCHI, 2014).

Entretanto, aquele que desenvolve esse ciclo junto a construção da política pública, segundo o autor, é o representante do Estado; um ator institucional que para alcançar seus objetivos assume e defende essa mesma perspectiva linear. Sobre essa afirmativa se desenvolve um corpo crítico, como afirma Boullosa (2013), que começa a relativizar o conceito de racionalidade em diferentes profundidades. Baseado nessa perspectiva crítica do conceito discutiremos aqui a possibilidade de desviar o fazer institucional, possibilitando, por exemplo, ao subalterno a contribuição no processo decisivo. Por esse motivo nos debruçaremos abaixo sobre esse subalterno e sua relação com o Estado enquanto ator.

A subalternidade, que propõe a existência da figura do subalterno, sugere um ampliado entendimento da realidade de exploração e dominação do trabalhador e do campesinato, entendendo que, essa realidade em verdade ultrapassa um fim sobre si mesmo. Formata-se como parte de uma premissa maior que se consolida historicamente como instrumento, sujeito e resultado dos processos de dominação. Logo, o termo em si refere-se a subordinação que sistemicamente acontece por meio de classe, gênero, raça, língua, entre 
outros, de maneira a evidenciar que todas as relações históricas são perpassadas por processos de dominação (GALASTRI, 2014; PRAKASH, 1994).

Gramsci entende a subalternidade como um grupo que possui "vida própria, à parte, instituições próprias" (GRAMSCI, 2002, p. 138), estando no espaço de 'margem' das instituições sociais e da própria sociedade civil. Compõe-se como um grupo essencialmente, sob domínio da hegemonia ativa das classes dirigentes que antes se representavam por grupos sociais específicos, e são agora manifestados através da própria persona institucional do Estado. Ou seja, o estado de dominado acompanha as mudanças que os agentes de dominação sofrem através do tempo, contudo, ainda que se altere o grupo dominante - da nobreza, ao clero, à burguesia, ao Estado - instigando mudanças ao processo de ser dominado, não há impacto na estrutura de dominação.

Outra relação é a afirmativa de Gramsci que define a 'classe subalterna' como grupo. Conquanto, mesmo que configure um grupo, o autor deixa claro que este não possui a possibilidade de se unificar enquanto Estado, tal que a "Unidade histórica das classes dirigentes acontece no Estado e a história delas é, essencialmente, a história dos Estados e dos grupos de Estados" (GRAMSCI, 2002, p. 139). Assim, Gramsci afirma que o subalterno não possui, por vias estatais, a possibilidade de tirar de si o estado de subalterno enquanto coletivo, pois caso tente fazê-lo tomará parte ativa no próprio processo de dominação.

Com isto, fica claro que o subalterno não tem de maneira natural parte ativa nos processos estatais e seus derivados, e tem como parte de seu próprio processo histórico formativo o Estado como agente dominante. Da mesma forma, o Estado, ao se fazer dominante reitera a impossibilidade de representações políticas democráticas por meio do fazer institucional estatal, o que justifica a hipótese de que; a participação do subalterno em um processo realizado fundamentalmente pelo Estado seja inalcançável, ainda que este carregue a alcunha de democrático.

O protagonismo do Estado entendido do processo de dominação, reitera-se e justifica-se no campo de estudo de políticas públicas, visto através da racionalidade pragmática de Lasswell (1951). Esta impõe uma barreira à contribuição do subalterno focada no processo de tomada de decisão, mas presente também nas demais esferas de contribuição da formulação política, já que são todas protagonizadas pelo mesmo ator. Essa impossibilidade intrincada ao campo pelo autor é refletida por críticas de diversos autores, em especial, de Dryzek (2006) que apresenta substancial debate entre a relação democracia e racionalidade que Lasswell pressupõe unidos em sua obra.

Dryzek parte da linha teórica de Hannah Arendt e afirma que a "política autêntica consiste não apenas em jogos estratégicos de poder, mas na interação de opiniões" (DRYZEK, 2006, p. 99, tradução nossa), insuflando o caráter participativo da democracia. Reconhece que a racionalidade pressupõe a retirada ou preterimento dessa participação, a partir da definição de um único ator que interpreta, analisa e constrói estratégias para lidar com os problemas coletivos através da policy orientation. Tudo isso encarcerado na figura 'onisciente' do policy maker (governamental).

Ressalta ainda, o autor, que "Hannah Arendt implica que nenhuma reconciliação entre democracia e racionalidade é possível, pois o autenticamente político e o "social" são dois domínios inimigos" (DRYZEK, 2006, p. 99, tradução nossa), afirmando não apenas irreconciliável a associação entre ambas, mas estabelecendo relação direta entre a racionalidade pragmática e o levante de uma realidade política tirânica. Esta por sua vez, não sob os parâmetros que Lasswell teoriza alicerçada em governos autoritaristas, mas entendendo-a como um "processo político controlado pela elite que anula os desejos e aspirações das pessoas comuns" (DRYZEK, 2006, p. 98, tradução nossa).

Esse controle desenhado teoricamente por Dryzek (2006) reverbera à realidade institucional idealizada por Gramsci enquanto sociedade influenciada por e para grupos hegemônicos. Gramsci ao entender que "o Estado é certamente concebido como organismo próprio de um grupo, destinado a criar as condições 
favoráveis à expansão máxima desse grupo" (GRAMSCI, 2007, p. 41) evidencia que o Estado exerce papel ativo por e para as classes dominantes em detrimento da sociedade e do subalterno em dimensões amplas.

Assim sendo-o, Dryzek afirma que o

[...] mainstream da análise política pode conceber a racionalidade apenas em termos instrumentais e tecnocráticos. No entanto, mesmo a eficácia desse tipo de racionalidade é suspeita quando se trata de problemas sociais de qualquer complexidade [...] (DRYZEK, 2006, p. 104, tradução nossa).

Evidenciando que a racionalidade linear proposta por Lasswell (1951) é não apenas insuficiente, mas inexpressiva às possibilidades do sujeito como coletivo à participação do processo político.

Quando explana suas críticas, Dryzek (2006) utiliza-se da democracia para afirmar que a racionalidade proposta pelo autor; submete e compõe um processo que desqualifica a totalidade da organização social no processo de entendimento, estudo e construção do problema, desqualificando assim a própria percepção do público a partir do institucional. Ao fazê-lo apoiado na proposição de Lasswell (1951) a Policy Science torna-se fundamentalmente incompatível com a própria proposição não apenas de ciência, mas de democracia.

Deve-se ressaltar também que as críticas à racionalidade apresentadas por Dryzek (2006) reafirmam a barreira entre a construção da política pública e os cidadãos comuns, destacada através da subalternidade como uma barreira entre o Estado e o subalterno. Mas como fazer para destituir essa barreira? Gramsci (2002) afirma que, o domínio das classes dirigentes se faz através do Estado, de maneira a alienar a própria percepção de "espontaneidade" da população. Dessa forma, as ações do Estado tendem a atuar organicamente contra o subalterno, fazendo com que o próprio aja a favor da manutenção do dominante

No sentido de que não se devem a uma atividade educadora sistemática por parte de um grupo dirigente já consciente, mas que se formaram através da experiência cotidiana iluminada pelo "senso comum" (GRAMSCI, 2007, p. 196-197).

Assim, a impossibilidade de participação e representação em construções estatais, não se deve apenas pelo vão entre o subalterno e o aparelho estatal dominante, mas pela relação que possui consigo mesmo e com a sociedade que o cerca, para além das construções lógicas que racham ou reafirmam a lógica de dominação atual. Logo, não há uma barreira específica entre o Estado e o subalterno, há apenas atores que "produzem e reproduzem estruturas relacionais que, ao mesmo tempo, agem sobre eles" (ABERS; SILVA; TATAGIBA, 2018, p. 18) no sentido de que as relações estruturais se reproduzem em uma sistemática tomada pelo senso comum que impõe limitações à relações que o subalterno estabelece com o social e, consequentemente, com o estatal. Essas limitações não nascem da racionalidade, mas encontram através desta, proposta inalterada da lógica de ação e, oportunidade para perpetuar-se através do fazer público.

Dessa maneira, entende-se que, não há 'barreira' para desconstrução, mas relações à organização social que devem ser também ampliadas e discutidas. Para isso, outro trabalho que se coloca como crítica a proposta racional de Lasswell, e se aloja em complemento a crítica de Dryzek é a realizada por Deborah Stone (1988) quando debate o processo de decisão e formulação política a partir de um modelo que difere do Market model. Para a autora a sociedade de mercado constrói um sistema social no qual; indivíduos buscando seu próprio bem-estar, trocam coisas por outras que sejam mutuamente benéficas aos envolvidos, estando, entretanto, preocupados único e exclusivamente consigo mesmos.

Os participantes em um mercado competem entre si por recursos escassos; cada pessoa tenta adquirir itens pelo menor custo possível e converter matérias-primas em itens mais valiosos para vender pelo preço mais alto possível. [...] No modelo de mercado, os 
indivíduos agem apenas para maximizar seus próprios interesses (STONE, 1988, p. 19, tradução nossa).

Stone sugere seguir um modelo de ação alternativo ao de mercado, identificado por ela como model of the polis. Para a autora, politics e policy são construções obrigatoriamente associadas a comunidade. Comunidade esta que encontra seu ponto de partidas na Polis. Escreve que, "Políticas Públicas tratam de comunidades que tentam alcançar algo como comunidades" (STONE, 1988, p. 20, tradução nossa). Portanto, para Stone a comunidade seria o ponto de partida para a análise e construção política, entendendo-a como centro conflituoso, mas que, ao atuar como grupo, expõem objetivos comuns aos cenários políticos.

A existência de objetivos comuns, que movem o coletivo como conjunto, age enquanto cerne diferencial frente a sociedade de mercado reforçando para o model of the polis, a necessidade de sempre assumir junto às políticas públicas a 'vontade coletiva' e o 'esforço coletivo'.

A construção da lógica de comunidade apresenta no contexto gramsciano um processo facilmente identificável como de benefício do subalterno, vez que segue dois pressupostos apresentados pelo autor. Primeiro que;

Com frequência, os grupos subalternos são originalmente de outra raça (outra cultura e outra religião) em relação aos dominantes e, muitas vezes, são uma mistura de raças diversas, como no caso dos escravos (GRAMSCI, 2002, p. 138).

O entender-se como comunidade, sendo de outra raça, cultura ou religião, possibilita, primordialmente, o entender a si e ao diferente como igual subalterno, identificar seu local de dominado e dessa percepção social unir-se enquanto comum contra o estado de dominação. Perceba, sob esse olhar não se destacam estratégias específicas de cooperação ou estratégias de manutenção política, a comunidade apresenta-se aqui como um pressuposto maior que rompe com a premissa linear ao Estado e, principalmente, com a assunção homogênea deste, admitindo que o Estado é na verdade uma conformação de comunidades, definindo o mesmo, caso democrático, como "um espaço genuinamente heterogêneo" (HALL, 2008, p. 87), bem como o próprio estado de subalternidade. Sendo possível, dessa maneira, identificar a contraposição expressa, não apenas pela obra de Gramsci, mas pelo que apresenta Dussel (1971) em 'lo outro' e 'el outro' e Mignolo (2000) em subalternidade "interior" e "exterior" (MIGNOLO, 2000, p. 175).

O segundo pressuposto, parte da ideia de que a existência do subalterno como coletivo identifica seu lugar de fala, e assim, suas impossibilidades a contar das 'modernidades impostas', podendo agir em favor da crise de autoridade que acomete as classes dominantes, o que possibilita a desqualificação da classe dirigente para unicamente dominante "detentora da pura força coercitiva, isto significa exatamente que as grandes massas se destacaram das ideologias tradicionais, e não acreditam mais no que antes acreditavam" (GRAMSCI, 2007, p. 184). Isso tudo, entretanto, habita na possibilidade teórica do subalterno conseguir estabelecer-se como comunidade, no sentido de não ascender enquanto organização estatal, haja vista, que essa possibilidade já fora a cima negada pelo autor.

Ainda trabalhando a ideia de comunidade, a proposição de Stone explana uma realidade muito mais ampla por trás da linearidade racional de Lasswell (1951). Permite perceber que ao localizar o campo, proposto pelo autor, fora da sociedade de mercado e admiti-la essencialmente de e para a polis, entendida como conjunto de comunidades, sua construção analítica não consegue seguir esta proposta quando baseada na perspectiva de Harold. É necessário extrapolar as proposições tecnocratas admitidas e realocar as linhas de ação à realidade individual das pessoas que influenciadas pelo coletivo e, assim, construídas pelo social - entendendo o subalterno, ainda como desqualificado a compor socialmente essa construção desenvolvem seus processos políticos. 
Dessa forma, percebemos que a destituição, ainda que parcial do protagonismo do Estado corrobora à composição de um ator mais plural para a política pública, respaldado na proposta democrática original. Todavia, tomando o Estado ainda como partícipe, a narrativa sugerida para a política mante-se como do e para o Estado, se não para elites específicas, visto que ainda como classes dominantes a coerção contra as grandes massas se realiza. Assim, julga-se necessário ampliar o escopo do debate à composição argumentativa da política e entender a importância de sua influência na coerção social. Por isso, na próxima sessão será ampliado o debate sobre o impacto da construção social neste processo desde a construção narrativa, entendendo-a como influente para a possibilidade participativa do subalterno.

\section{Realidade Política e possibilidades Críticas Argumentativa}

O trabalho de Stone (1988), não apenas lançou luz sobre as disparidades entre o modelo racional - tido como hegemônico - e a realidade comunitária da policy, mas também se lançou na oportunidade de pressupor uma série de características, até então não discutidas sobre a formulação de políticas públicas. Uma vez entendido que apoiado na comunidade e no coletivo a existência das políticas públicas e seu processo formativo diferem daqueles estabelecidos no modelo de mercado. Sugere-se, portanto, a necessidade de entender pressupostos novos e ainda não teorizados a partir dessa realidade comunitária (re)alocando esses processos e suas possibilidades à polis.

Todavia, a autora não desenvolve suficientemente o conceito de comunidade enquanto crível a diversidade. Entende-se que ao afirmar comunidade como categoria primária, esta é conceituada como: coletivo de indivíduos unidos por laços sanguíneos, familiares, religiosos, entre outros. Ora, assumindo que a conformação em comunidades como proposto, seja uma possibilidade real para o subalterno, deve-se atentar as dificuldades de identificar-se enquanto comunidade alicerçada em recortes diversos como gênero, raça e diferenças sexuais, pois o estado de subalterno, ainda que visto por Gramsci enquanto grupo, se lavra por realidades sociais diversas (PRAKASH, 1994).

Contudo, pode-se argumentar que essa mesma diferença/diversidade seja a força motriz para a construção de comunidades ao subalterno. Comunidades não necessariamente nascem da homogênea semelhança, ainda que imprimam um senso de identidade específica para seus membros. Essas precisam de aspectos formadores no qual pessoas se identifiquem, formando comunidades culturais, comunidades trabalhistas, entre outras. Logo, não apenas é possível a conformação de pessoas diferentes em uma única comunidade como também é, afirmar que "as pessoas pertencem a várias "comunidades" sobrepostas que por vezes exercem pressões contrárias" (HALL, 2008, p. 79). E é justamente essa pressão contrária que possibilita o fazer democrático dentro do Estado.

Dessa forma, sim, a conformação comunitária é factível para o subalterno. Mas surge como questionamento: até que ponto as realidades do estrato mais baixo, social, político e econômico conseguem utilizar dessa estratégia para desafiar os modelos de racionalidade e ação social contrastando o fazer em comunidade ao fazer institucional (HALL, 2008; MIGNOLO, 2017; PRAKASH, 1994).

Embora Stone (1988) não se aprofunde em específico na construção de comunidades plurais, isso não impede a autora de desenhar sua crítica ao paradigma do processo de formulação política, bem como, daquilo envolvido e tido como relevante ao desenvolvimento da "arte de tomar decisões políticas (tradução nossa)" - se opondo, dessa forma, a características da Policy orientation. A autora firma uma série de pressupostos além dos pensados por Lasswell, nomeados de laws of passion, permitindo discutir com maior afinco a construção política coletiva, destacando entre o jogo político o 'poder' e sua disputa como fundamento a sujeitar o policy maker, seus interesses e as alianças políticas que estabelece.

Poder é um fenômeno das comunidades. Seu objetivo é sempre subordinar o interesse pessoal individual a outros interesses - às vezes a outros interesses individuais ou de grupo, às vezes ao interesse público (STONE, 1988, p. 34, tradução nossa). 
A partir, da ideia de poder, Stone (1988) nos apresenta não apenas que as preferências individuais são construídas socialmente e influenciadas pelo coletivo, mas que são também, motivo de disputa no jogo político de alianças e influências, fundamentadas nas linhas de poder dispostas no cenário político. Essa percepção da noção de construção social por trás dos processos políticos são a base para o que ficou conhecido como análise interpretativa de política pública, sua aplicação parte principalmente dos trabalhos de Majone (1989) e Fischer (1993), bem como dos complementos já apresentados a cima por Stone.

Majone (1989) discute a potência persuasiva e a influência presente na prática discursiva como associadas ao jogo político, apoiado na razão de que ideias e alianças podem ser influenciadas por tais instrumentos dentro da lógica argumentativa, caracterizando a análise de políticas pela habilidade em construir argumentos,

A argumentação é o processo fundamental que os cidadãos e os governantes seguem para chegar a juizos morais e à eleição de políticas. A discussão pública movimenta o conhecimento, a experiência e o interesse de pessoas que concentram sua atenção em um número limitado de problemas (MAJONE, 1989, p. 37, tradução nossa).

Ao lançar o poder do discurso como de influência direta, não apenas à construção social, mas como parte desta no papel de assumir influências ao desenvolvimento dos processos políticos, Majone sugere a persuasão como unidade de análise à análise política, indicando sua aplicabilidade, principalmente, à dimensão institucional, em que reside a tecnocracia de Lasswell. Para a autora, a verdadeira análise de políticas públicas reside no "ejercício de modelación", atentando-se as normas argumentativas e a estrutura intelectual do discurso público (MAJONE, 1989, p. 41).

A assunção da argumentação é discutida por Fischer (2013) sob o que chama de 'virada argumentativa'. Antes tal perspectiva, ele percebe a construção política como um fato sobre si mesmo, a partir do momento que seu processo admite a construção finalística daquilo que percebe como real, uma vez que, atuará sobre esse real também de maneira finalística. Assim, tanto o processo político como a política pública em si constituem-se argumentativamente, para si e para o social, bem como somadas as influências recebidas e exercidas sobre seus respectivos contextos (FISCHER, 2016a; FISCHER; FORESTER, 1993)

Fischer percebe que a análise política excede a mera construção tecnocrata ou a simples consolidação do entendimento social pelo policy maker, mas coloca-se como "consequência de movimentos dentro dos processos de um discurso político maior" (Fischer e Forester, 1993, p. 145-146, tradução nossa). Para utilizar da argumentação como unidade de análise e percebê-la como fundamento passivo e ativo das linhas de poder dentro do jogo político, sob influências políticas, é necessário além de perceber e entender, interpretar os fenômenos sociais, a partir de suas próprias realidades, e assim traçar no processo político aquilo que o integrará, ato no qual se coloca a 'virada argumentativa' sugerida no 'framing' do autor.

A contar do entendimento argumentativo da análise política, percebe-se um outro viés para discutir políticas públicas; a manutenção do discurso público. Argumenta-se que o ator ao participar da política pública, é não apenas aquele que propõe e conforma as possibilidades de decisão, mas aquele que melhor constrói argumentativamente sua proposição, e convence o coletivo de que argui sobre a realidade. Deste entendimento, para discutir a participação do subalterno como ator político, deve-se discutir também a possibilidade argumentativa que possui na esfera pública, escapando das proposições gramscianas para discuti-lo.

Assim, definiremos também um grupo subalterno em específico, a fim de exercer melhor capacidade analítica, partindo então da subalternidade afirmada na colonização e seus efeitos, conhecidos como colonialidade (BERNARDINO-COSTA; GROSFOGUEL, 2016). Discutir desse espaço de fala, implica a 
existência de um grupo hegemônico bem delimitado que exerce três tipos de colonialidade: do saber, do poder e do ser, relacionando todas a própria construção corporal do sujeito (MALDONADO-TORRES, 2018).

O que quer que um sujeito seja, ele é constituído e sustentado pela sua localização no tempo e no espaço, sua posição na estrutura de poder e na cultura, e nos modos como se posiciona em relação à produção do saber (MALDONADO-TORRES, 2018, p. 43).

Dessa forma, subjugar o sujeito enquanto colonizado perpassa essa tríplice colonialidade, de maneira que sua própria subjetividade seja dominada. Isso faz do próprio sujeito um espaço contínuo de luta entre a instituição colonial - e o status quo do mundo de dominação - e a sua própria subjetividade, negando-lhes não apenas espaço de fala, mas sugerindo que deste processo a produção argumentativa do subalterno agiria fundamentada em experiência e posicionamento cultural que não mais the pertence, da localização no tempo e no espaço que não lhe é facultada e na produção do saber que não lhe é espontânea. Poderia, ainda assim, o subalterno falar? (BERNARDINO-COSTA, 2018; MALDONADO-TORRES, 2018).

Spivak (2014) ao debruçar-se sobre a narrativa do subalterno a localiza criticamente, a partir do essencialismo histórico, e ao fazê-lo o caracteriza como inexistente, pois não é cedido espaço para tal narrativa dentre a discursiva hegemônica. Entretanto, essa mesma narrativa é passível de constituir-se como possibilidade através de processos à representatividade. Ao explanar tais processos afirma que se fazem possíveis em duas vertentes, considerando "o jogo de vertreten ("representar" em seu primeiro sentido) e darstellen ("re-presentar" no segundo sentido) [...]" (SPIVAK, 2014, p. 41).

O primeiro, [Vertretung] é caracterizado como a falta de sujeitos plenos e instituídos de poder para fazê-lo, assumindo a falta de capacidade do subalterno em se auto representar; e o segundo, [Darstellung] como a representação feita por encenação, coloca assim um sujeito que encena o estado de subalternidade para exercer a fala para e por este. Dessa maneira, o subalterno é caracterizado como um agente destituído de poder, impossibilitado de falar se não por meio de linhas erráticas e desarticulantes; propostas, mediadas e protagonizadas pelo próprio grupo hegemônico. Ao dispor da argumentação proposta por Majone como um instrumento de poder no processo político, vê-se o subalterno como impossibilitado de exercê-lo; e, entendendo a proposta de Fischer (2013), impossibilitado de construir ou participar do processo de construção da política pública.

É possível, assim, traçando conceitualmente de Stone (1988), localizar que o entendimento do que são políticas públicas escapa da conceituação singular, já afirmado assim pelo campo de Lasswell (1951), e que se constitui, outrora, enquanto construção realística dos objetivos essenciais ou tidos como à Pólis. Essa construção pode ser destituída aos poucos da linearidade presente na proposta original do campo, o que permite a assunção de atores outros a sua construção. Mas a verdadeira influência argumentativa deste novo ator para com a construção factível da política pública, não se concretiza em totalidade o que surge como uma ainda presente impossibilidade teórica à participação do subalterno.

Outra afirmativa é a possibilidade de atores no plural. Ao ampliar o pressuposto teórico da subalternidade incluindo o debate colonial/decolonial e o subaltern studies, se discute realidades outras ao próprio estado de subalternidade, que dessa maneira, multiplica-se enquanto processo, mas que integra ainda, a mesma estrutura de dominação realizada por uma classe dominante/dirigente fundada na unidade do Estado.

Dessa forma, ainda há impossibilidades à participação do subalterno tanto pelo corpo crítico do campo, como por pressupostos a subalternidade. Todavia, percebe-se que o processo da política pública, como consequência da proposta crítica argumentativa se baseia na perspectiva de que o próprio argumento elucida o problema no qual baseia-se a política pública em si. Por isso, o que forma a política pública de maneira finalística não é essencialmente o argumento, mas a capacidade do ator em eleger o problema a ser tomado como da coletividade. 
Com isto, na próxima sessão ampliaremos a discussão sobre, como o subalterno se relaciona com a eleição do problema na política pública, entendendo de que forma esse problema é eleito a partir do Estado, resgatando algumas das propostas teóricas anteriormente apresentadas a fim de sugerir a conformação de uma proposta que sugere o próprio subalterno como eleitor do problema, assim dá própria políticas pública.

\section{As possibilidades políticas em (des)favor ao Subalterno}

Percebemos que, a participação social ou a representação política como processo presente as políticas públicas não surgem com o ator multidisciplinar, tecnocrata e positivo de Lasswell (1951), ou mesmo em sua falha tentativa ampliativa em (1971). Compreende-se a partir de Dryzek (2006), somados os pressupostos de Stone (1988), Majone (1989) e Fischer (1993) (2016b), que entendem a racionalidade de Lasswell como insuficiente para compreender a complexidade da formulação política como produto social e, portanto, sujeitos a fenomenologia social

Partindo deste entendimento, alguns pontos devem ser traçados para indicarmos possibilidades transversais ao processo que subverte a subalternidade enquanto corpo político. O primeiro aspecto é a existência de produções políticas criadas para lidar com essa subalternidade, em que se destacam, por exemplo, as políticas sociais.

Essas políticas,

[...] ora são vistas como mecanismos de manutenção da força de trabalho, ora como conquistas dos trabalhadores, ora como arranjos do bloco no poder ou bloco governante, ora como doação das elites dominantes, ora como instrumento de garantia do aumento da riqueza ou dos direitos do cidadão (FALEIROS, 2006, p. 8)

A política Social, que age como reflexo do modelo do ciclo de política pública, ao atuar em tantas perspectivas, permite a si mesma se instrumentalizar em um agir que muito remete ao de uma moeda, atuando como um constructo em capital que atende o anseio político de ambos os lados. Para lidar com as necessidades das elites compõe-se como política, intrinsecamente, relacionada a políticas econômicas, criadas em meio ao estabelecimento e evolução do capitalismo, e constituídas para melhor funcionamento do mesmo (BEHRING, 2006; PIANA, 2009). Para lidar com as necessidades dos demais grupos, compõese como conjunto de orientações guiadas pelo Estado e instituídas com base no conceito de Proteção Social, que possui em teoria, o anseio de atuar fortalecendo os processos estruturais fragilizados dos grupos sociais mais vulneráveis (DEVEREUX; SABATES-WHEELER, 2004).

Interpretamos novamente que, independente da linha seguida para a definição de seus objetivos, caso seja guiada pela linearidade de Lasswell (1951), a construção da política pública compõe-se como processo que tende a desestruturar qualquer possibilidade ativa ao subalterno, vez que age naturalmente de fora para dentro. No caso da política social, propõe que estes passem a compor um público economicamente ativo ao capital - suprindo as necessidades das elites, desempenhando um papel público que por vezes, supre apenas as necessidades do capitalismo em detrimento do real problema subalterno.

Como consequência, identifica-se uma segunda perspectiva de ação da política pública. O subalterno que é naturalmente dominado do Estado, se torna dentro da política social o próprio problema tomado como de necessária a atuação pública. A ação pública sobre esse específico grupo dentro da análise a cima, acontece no sentido de forçar seu agir - nesse caso convergindo para o capital, adotando como sua a lógica de produtividade do capitalismo.

Retira-se em definitivo do devir político a ideia de que seria um projeto democrático; "um projeto de autonomia" e a realização de um "acordo em uma coletividade mediante comunicação e reconhecimentos" (MBEMBE, 2018, p. 9); e faz da própria ação política um dispositivo que coopta a possibilidade participativa 
da sociedade. Mas ao contrário do que já afirmava Dryzek (2006), vê-se um movimento que ultrapassa essa afirmativa, e ao invés de apenas subverter o espaço de contribuição dos demais, aponta o próprio subalterno em seu existir como o problema político a ser combatido enquanto Estado, muito próximo do sentido teórico que Mbembe (2018) dá a soberania e sua aplicabilidade biopolítica.

Sob essa lógica, é possível notar a construção do problema para suscitar a política pública, não construída sob, ou apenas do meio externo para o interno, mas contra o olhar do subalterno. A percepção desta lógica reafirma um mundo "dividido em compartimentos, este mundo cindido em dois" (FANON, 1997, p. 29), e essa divisão justifica não apenas a espontaneidade elucidada por Gramsci (2002), a colonialidade exposta por Maldonado-Torres (2018), e o essencialismo histórico de Spivak (2014), bem como a manutenção destas, pressupostas no processo político à linearidade em Lasswell (1951).

Essa percepção não é diferente quando interpretada a partir da mirada ao revés, que afirma o problema como reflexo do interesse público, o "interesse da comunidade (BOULLOSA, 2013, p. 76). Boullosa afirma a política pública como um fluxo aberto de interações, em que o problema ao ser tomado como público emerge à agenda pública e passa a ser influenciado pelos diversos atores que buscam governar tais problemas. Estes o fazem "de acordo com suas compreensões de tais problemas ou bens, mas também de acordo com seus poderes de governabilidade, de mobilizar de recursos e de influenciar os demais atores que conformam" (BOULLOSA, 2013, p. 78).

A autora critica a ideia de atores neutros no processo político e sugere, ao propor a mirada ao revés, que compreendamos um cenário de disputa, em que apesar disso o Estado ainda caracteriza-se como o ator central, sem o qual "dificilmente ter-se-iam fluxos razoavelmente robustos de políticas públicas capazes de mobilizar e atrair análises mais consistentes". Entretanto, ainda assumindo papel central, há uma proposta à multiatorialidade dentro desse conceito indicando que, deve sim haver um fluxo de disputas influentes excedendo o Estado e composto por arenas públicas diversas, que não conseguem controlar exclusivamente tanto a eleição dos problemas quanto a organização das ações públicas a respeito (BOULLOSA, 2013).

Embora esta proposta analítica nos permita sugerir o subalterno como partícipe destas arenas políticas, nos enraizamos também naquilo que afirmamos anteriormente como "espontaneidade" do paradigma dominante, em que os atores todos, partícipes ou não do processo, têm o subalterno justamente no espaço que the cabe, fora do fluxo decisivo à ação pública, impedido de fazer junto e de propor tanto problema como resposta. Na oportunidade de entender que todas as arenas estejam conscientes da experiência cotidiana que é a reafirmação do espaço à margem do subalterno, seu lugar como problema coletivo é afirmado em comunidade (BOULLOSA, 2013; GRAMSCI, 2007).

Entende-se que, a percepção do subalterno como problema é clara e real, e possibilita a manutenção do seu estado de subalternidade. Mas que parte dessa manutenção se deve à realidade de auto entendimento do estado de subalternidade, visto como já afirmado, que "As classes inferiores, estando historicamente na defensiva, não podem adquirir consciência de si a não ser por negações” (GRAMSCI, 2007, p. 190).

Dessa forma, para quebrar a construção de que o subalterno é o problema, devemos voltar a trabalhá-la como uma condição heterogênea de grupos sociais que incluem classes e não classes (grupos política e socialmente marginais, esparsos e desagregados)" (GALASTRI, 2014, p. 44). Como estados do ser que se manifestam para além do ter ou não ter acesso aos modos de produção, e que por isso, precisam ser debatidas outras linhas do próprio estado de dominação intencionadas pela institucionalidade estatal, abrindo possibilidades a construções que escapem das linhas estatais e permeiem o auto reconhecimento como comunidade.

Para isso, podemos trabalhar a análise feita por Cortes (2015) que acompanha a atividade política do Conselho Nacional de Assistência Social (CNAS) do Brasil fundamentada no conceito de Policy Community. A autora interpreta o conceito como a conformação de um pequeno grupo de atores que possui valores $\mathrm{e}$ 
visão coerentes entre si, a respeito da organização de uma política setorial, e que dessa forma podem exercer influências e tomar providências políticas favoráveis para sua causa. Cortes (2015) faz questão de destacar a organização setorial que as policy Community conformam, agindo sempre fora do processo político visível, que foi na oportunidade analisada pela autora a maneira com que os conselheiros do CNAS conseguiram fazer do próprio conselho um centro normatizador e re-afirmador do Sistema Único de Assistência Social (SUAS).

Todavia, o caráter setorial da Policy Community e sua existência por entre a ação estatal dificultam a utilização do conceito como resolutivo para discussão do estado de subalternidade. Cada setor de política pública interage diferente com o Estado e com o resto da sociedade, ao mesmo tempo que a efetiva atuação dessas 'comunidades' dependeriam da efetiva inclusão do subalterno como ator livre e participativo do sistema político. Motivo pelo qual conceitos outros como insider activism - que pressupõe o confronto político dentro do contexto institucional - frente a racionalidade de Lasswell, colocam-se como pouco prováveis a resolução (ABERS; SILVA; TATAGIBA, 2018; LEITÃO; SILVA, 2017).

Devemos portanto, retomar a proposta de comunidade em Stone (1988) e a construção política como resultado desta, mas unindo também o proposto por Hall (2008) esclarecendo que não se forma uma comunidade, mas comunidades que interagem e pressionam umas às outras e que a partir dessa relação mantem-se a característica heterogênea da democracia presente a estas (DRYZEK, 2006).

Ainda ao aplicar todo esse pressuposto, o subalterno não participa da formação política, pois entende-se que a racionalidade proposta o impede. O Estado perde o posto de ator único, mas ainda age como protagonista, e ao construir junto com o subalterno e demais atores, elege a este o problema tido como da sua própria coletividade. Vez que, como evidenciada ainda na sessão anterior, o Estado - e seus representantes - é quem exerce poder através da construção argumentativa do problema e da política (BOULLOSA, 2013; LASSWELL, 1951; MAJONE, 1989).

Logo, argumenta-se que, para a participação factível e contributiva do subalterno à possibilidade política, não apenas a racionalidade deve ser de fato extirpada como seu pressuposto institucional. É necessária uma estratégia construtiva que rompa fundamentalmente com toda a raiz linear da proposta feita por Lasswell (1951). É preciso uma proposta tão radical quanto a reconfiguração pós-nacional trazida pela política multicultural (HALL, 2008).

Para isso, argumenta-se uma proposição que ultrapasse as possibilidades apresentadas pela construção estatal, que não se limite ao que há estabelecido dentro do espectro político-institucional. Deve-se, nesse sentido, fundamentar-se na própria comunidade, de dentro para fora do que é vivido e desejado pelo comunitário-coletivo, num ímpeto que muito se assemelha ao community-based social protection discutido por Ratuva (2014). De maneira que não se tente incluir ou somar a participação comunitária em processos político-institucionais, mas que toda a construção adotada pelo institucional, seja feita fora dele, um movimento de fora para dentro invertido (THEMUDO, 2002).

Ratuva (2014) evidência algumas categorias fundamentais da community-based social protection, em que afirma o 'parentesco' e a 'reciprocidade' como princípios para seu desenvolvimento. Sua aplicabilidade é tamanha que os processos institucionais desenvolvidos para lidar com a proteção social em comunidades, não conseguem penetrar o tecido social comunitário e se rende as possibilidades já criadas pelo próprio coletivo. Novamente, sua aplicabilidade depende da própria construção de identidade comunitária que se sugere conquistar pelo subalterno, ainda assim, na possibilidade de conquistá-la esta caracteriza-se como uma proposta que transpassa construções lineares e que destoa do proposto pelas possibilidades institucionais criadas por Lasswell.

Percebe-se nesta proposta não apenas a desinstitucionalização, mas a afirmativa da política pública como uma experiência comunitária de si para si. Que ao fugir inteiramente do institucional, ainda possibilita a organização de ações coletivas, mas próprias, fazendo da política pública nesse sentido uma experiência 
pública, feita, vivida e analisada em comunidade. Aberta à possibilidade de cooptação ao Estado, mas que para plena funcionalidade, deste não precisa. Oportunidade em que o subalterno tem plena liberdade para eleger seus problemas e a partir disso deliberar enquanto comunidade como lidar com esta.

\section{Considerações Finais}

A proposta linear e racional que baseia o campo das Políticas Públicas é o ponto cerne do questionamento feito do início ao fim do presente texto. Em sua essência, o campo fundado por Harold Lasswell fecha suas portas a possibilidade formativa única e exclusiva de especialistas, do governo e de seus representantes, dificultando a participação não apenas de outros públicos, mas tornando impraticável sua contribuição real.

O questionamento feito baseava-se na ideia de como o produto público, a política pública, deveria focar-se a todos que compõe, ainda que a margem a esfera pública, incluindo, desta maneira, um ator que vive sob estado permanente de dominação de grupos dominantes, o subalterno. Com grande pressuposto teórico emergente a sua realidade, o artigo evidenciou as possibilidades que esse ator poderia desempenhar sob a ideia de participar na construção e atuação das políticas públicas.

Assim, a partir de quatro categorias analíticas principais: Estado, Ator, Argumento e Problema, foram apresentados e debatidas perspectivas críticas ao campo de políticas públicas, incluindo entre eles, Lindblom (1959, 1979), Tribe (1972), Dryzek (2006), Stone (1988), Majone (1989) e Fischer (2016b, 2016a; 1993; 2013), em busca de saídas a racionalidade linear que fechava as portas para a contribuição do subalterno. Foi estabelecida, em cada crítica feita ao campo das políticas públicas, uma relação com os pressupostos teóricos da subalternidade, apresentando possibilidades fundamentadas em autores como: Gramsci (2002, 2007), Maldonado-Torres (2018), Joaze Bernardino (2018; 2016), Spivak (2014), Mbembe (2018) e Stuart Hall (2008).

Embora, muitas possibilidades tenham sido propostas e debatidas, o fato do próprio Estado que é o protagonista na proposta racional ao campo de políticas públicas, ser aquele que encadeia os processos de dominação sob o subalterno, dificultava o encontro de saídas factíveis a participação do subalterno nas ações do campo, tanto ao ampliar o espaço de atores outros em detrimento a relação destes com o Estado, como nas possibilidades críticas de rearticular a lógica argumentativa e elucidativa ao problema. Por fim, encontrou-se como possibilidade única a sua realização, a oportunidade de o subalterno eleger, enquanto ator, o problema que será tratado como do coletivo à construção da política pública.

Para isso, tornou-se necessário desatar a proposta meramente interdisciplinar e reafirmar o multidisciplinar do campo como insuficiente a si mesmo. Não apenas contrastando a racionalidade fundamental que emanava das ações estatais, mas apontando a necessidade em ampliar a contextualização que torna relevante a construção social por trás da própria ideia de comunidade. A partir disso, sugeriu-se ainda a retirada em totalidade da própria participação do Estado na eleição do problema, possibilidade na qual conseguiu-se não apenas fazer do subalterno aquele que propõe o problema, mas aquele que propõe, vive e analisa a política em si, vez que, dessa forma, a política torna-se parte do fazer cotidiano da própria comunidade.

Importante também afirmar que, embora o pressuposto teórico subalterno não represente a sociedade enquanto completude, os achados do diálogo aqui estabelecido demonstram quão importante sua aproximação. Não obstante multidisciplinar o campo de estudos de políticas públicas necessita de contribuições outras para ampliar seu olhar às realidades específicas de atores que não participam e/ou tem rechaçados suas tentativas de aproximação aos processos de decisão política. Isso implica não apenas no entendimento da própria Política Pública, mas de sociedade, Estado e Democracia.

É necessário ressaltar que certas discussões foram preteridas durante a construção dessa crítica, afim de manter em foco a construção da política pública e possibilidades factíveis em como o subalterno poderia 
desta fazer parte. Dessa forma, aspectos como a construção de políticas específicas para além de temas macro estruturais como, Políticas de saúde, políticas de educação, políticas de distribuição de renda, que são ambas políticas sociais, não foram abordadas em específico, mas poderiam a partir do pressuposto teórico construído. Da mesma maneira, não foram especificadas comunidades subalternas para além do necessário à discussão do referencial proposto.

Por fim, vê-se como necessário a amplitude de estudos críticos que levem em consideração não apenas a subalternidade, mas a exclusão social e a participação dos extratos sociais mais baixos na construção de políticas públicas, de maneira a forçar a emersão de um novo paradigma político, e um ciclo de políticas públicas menos linear, propondo não apenas intervenções pontuais, mas a reestruturação de um campo que está, ainda despreparado para a realidade que se propõe.

\section{Referências}

ABERS, R. N.; SILVA, M. K.; TATAGIBA, L. MOVIMENTOS SOCIAIS E POLÍTICAS PÚBLICAS: Pensando atores e oportunidades políticas. Lua Nova, v. 105, p. 15-46, 2018.

AGUM, R.; RISCADO, P.; MENEZES, M. Políticas Públicas: Conceitos e Análise em Revisão from the Technical to Ideas. Revista Agenda Política, v. 3, p. 12-42, 2015.

BEHRING, E. R. Fundamentos de Política Social. In: MOTA, A. et al (Ed.). Serviço Social e saúde: formação e trabalho profissional. São Paulo: OPAS, 2006. p. 1-27.

BERNARDINO-COSTA, J. Decoloniality, Black Atlantic and black intellectuals in Brazil: In search of a horizontal dialogue. Sociedade e Estado, v. 33, n. 1, p. 119-137, 1 jan. 2018.

BERNARDINO-COSTA, J.; GROSFOGUEL, R. Decolonialidade e perspectiva negra. Sociedade e Estado, v. 31, n. 1, p. 15-24, 2016.

BOULLOSA, R. D. F. MIRANDO AO REVÉS NAS POLÍTICAS PÚBLICAS: notas sobre um percurso de pesquisa. Pensamento \& Realidade, v. 28, n. 3, p. 67-84, 2013.

CORTES, S. V. Policy Community defensora de direitos e a transformação do Conselho Nacional de Assistência Social. Sociologias, v. 17, n. 38, p. 122-154, 2015.

DEVEREUX, S.; SABATES-WHEELER, R. Transformative social protection. IDS Working Paper 232. 2004.

DRYZEK, J. S. Policy Sciences of Democracy. Polity, v. 22, n. 1, p. 97-118, 2006.

FALEIROS, V. DE P. O que é política social. 5. ed. São Paulo: Editora Brasiliense, 2006.

FANON, F. Os condenados da terra. Rio de Janeiro: Editora Civilização Brazileira, 1997.

FISCHER, F. Para além do empirismo: policy inquiry na perspectiva pós-positivista. Revista NAU Social, v. 7, n. 12, p. 163-180, 2016a.

FISCHER, F. What is critical? Connecting the policy analysis to political critique. Critical Policy Studies, v. 10 , n. 1, p. 95-98, 2016b.

FISCHER, F.; FORESTER, J. The Argumentative Turn in Policy Analysis and Planning. London: Duke University Press, 1993.

FISCHER, F.; GOTTWEIS, H. The Argumentative Turn Revisited. The Argumentative Turn Revisited, 2013.

GALASTRI, L. Classes sociais e grupos subalternos: distinção teórica e aplicação política. Miolo Rev Crítica Marxista, v. 39, n. 35, p. 35-55, 2014. 
GRAMSCI, A. Cadernos do cárcere volume 5: O Risorgimento. Notas sobre a história da Itália Rio de Janeiro: Civilização Brasileira, 2002.

GRAMSCI, A. Cadernos do cárcere Volume 3: Maquiavel. Notas sobre o Estado e a política. Rio de Janeiro: Civilização Brasileira, 2007.

HALL, S. A questão multicultural. In: Da diaspora-identidades e mediações culturais. Belo Horizonte: UFMG, 2008. p. 51-100.

LASSWELL, H. D. The Policy Orientation. In: LASSWELL, D. L. H. D. (Ed.). The Policy Sciences: Recent Developments in Scope and Method. California: Stanford University Press, 1951. p. 1-15.

LASSWELL, H. D. A Pre-View of Policy Sciences. New York: American Elsevier, 1971.

LEITÃO, L. R. S.; SILVA, M. K. Institucionalização e contestação: as lutas do Movimento Negro no Brasil (1970-1990). Política \& Sociedade, v. 16, n. 37, p. 315-347, 22 dez. 2017.

LINDBLOM, C. E. The Science of Muddling Through; Public Administration Review, v. 19, n. 2, p. 79, 1959.

LINDBLOM, C. E. Still Muddling, Not Yet Through. Public Administration Review, v. 39, n. 6, p. 517-526, 1979. 